\title{
AN EARLY CLINICAL ASSESSMENT OF THE STEROID ANAESTHETIC MINAXOLONE
}

\author{
G.L. Dunn, D.H. Morison, J. McChesney and W. Pine
}

\section{ABSTRACT}

\begin{abstract}
Minaxolone, a new wate r-soluble steroid anaesthetic, was studied in combination with nitrous oxide in 30 healthy female patients. The objective of the study was to assess induction dosage, clinical efficacy, recovery characteristics, and frequency of side effects. It proved to be an effective anaesthetic causing only minimal cardiovascular and respiratory depression. Those side effects which occurred during operation were felt to be due in part to light anaesthesia and lack of analgesia. Excitatory movements and hypertonus occurred in seven patients during operation and in ten patients in the early recovery phase. Late recovery was impressive, both in quality and lack of side effects, and all patients were considered fit for discharge from hospital within four hours of the operation. Minaxolone appears to be a promising new anaesthetic worthy of further study.
\end{abstract}

STEROIDS WERE FIRST SHOWN by Selye in $1941^{1}$ to have anaesthetic properties. Alfathesin (a mixture of two steroids, alphaxalone and alphadolone) was the first steroid to be successfully used as a rapidly acting intravenous anaesthetic. Anaphylactoid reactions have been reported with its use, ${ }^{2}$ which may be partly attributable to the inclusion of "Cremophor EL" in its formulation. Initial animal studies ${ }^{3}$ indicated that Minaxo-

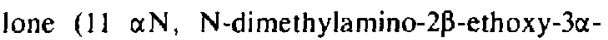
hydroxy-5 $\alpha$-pregnan-20-one citrate), which is a water-soluble steroid anaesthetic, appeared worthy of further study.

This report describes an early (Phase Il) evaluation of Minaxolone in patients. The objectives of the study were to assess induction dosage, clinical efficacy, recovery characteristics, frequency of side effects, and evidence of drug-related toxicity.

\section{METHODS}

Thirty fit female patients, undergoing elective therapeutic abortion or dilatation and curettage, were studied. Written informed consent was obtained from all patients before admission to the study. All patients were unpremedicated, and had been fasting for at least six hours. An intravenous infusion of 3.3 per cent dextrose in 0.3 per cent saline was started preoperatively.

G.L. DunN, M.B., B.S., F.F.A.R.C.S., F.R.C.P.(C), Associate Professor; D.H. Morison, M.B.Ch.B., F.R.C.P.(C), Associate Professor; J. MCChesney, M.B., Ch.B., Resident; W. PINE, B. Comm., M.D., Resident. Department of Anaesthesia, McMaster University, Hamilton. Ontario, Canada, L8S 4J9.

\section{Induction of anaesthesia}

Minaxolone $(5 \mathrm{mg} / \mathrm{ml})$ was administered intravenously by an infusion pump at approximately $6.5 \mathrm{ml}$ per minute.

In 15 patients, the Minaxolone infusion was discontinued when consciousness was lost as judged by lack of response to verbal command. but before abolition of the eyelash reflex (Group I).

In the remaining 15 patients, Minaxolone administration was continued until the eyelash reflex disappeared (Group II).

\section{Maintenance of anaesthesia}

Anaesthesia was maintained in both groups with 70 per cent nitrous oxide with oxygen delivered from a Quantiflex mixer at 8-10 litres per minute through a coaxial circuit. All patients breathed spontaneously and did not receive any vagolytic agent. Additional increments of Minaxolone equal to 25 per cent of the induction dose were administered when indicated, to maintain satisfactory anaesthesia. Fentanyl in $50 \mu \mathrm{g}$ increments was used only when judged desirable on clinical grounds. No volatile agents were employed.

\section{Physiological measurements}

The electrocardiogram was displayed continuously on a Hewlett Packard oscilloscope (model \#1308A). The following physiological variables were measured and recorded at one minute intervals before and during anaesthesia:

(a) Pulse rate, systolic and diastolic blood pressure were measured by and recorded from a Dinamap model 545 automated blood pressure recorder. 
TABLE I

Value Shown Is The MEAN \pm S.D.

\begin{tabular}{lccccc}
\hline \hline & $\begin{array}{c}\text { Age } \\
(\mathrm{yrs})\end{array}$ & $\begin{array}{c}\text { Weight } \\
(\mathrm{kg})\end{array}$ & $\begin{array}{c}\text { Induction } \\
\text { dose } \\
\left(\mathrm{mg} \cdot \mathrm{kg}^{-1}\right)\end{array}$ & $\begin{array}{c}\text { Patients } \\
\text { receiving } \\
\text { increments }\end{array}$ & $\begin{array}{c}\text { Total } \\
\text { dose } \\
\left(\mathrm{mg} \cdot \mathrm{kg}^{-1}\right)\end{array}$ \\
\hline Group I $(\mathrm{n}=15)$ & 25.3 & 58.3 & 0.63 & 13 & 0.82 \\
& \pm 5.08 & \pm 9.42 & \pm 0.113 & & \pm 0.168 \\
Group II $(\mathrm{n}=15)$ & 22.7 & 60.1 & 0.93 & 5 & 1.02 \\
& \pm 4.08 & \pm 7.78 & \pm 0.149 & & \pm 0.212 \\
All patients & 24.0 & 59.2 & 0.78 & 18 & 0.92 \\
( $\mathrm{n}=30)$ & \pm 4.74 & \pm 8.54 & \pm 0.205 & & \pm 0.208 \\
\hline
\end{tabular}

(b) Respiratory rate and minute volume were measured continuously with a Wright Electronic Respiration Monitor.

\section{Recovery times}

Recovery times were recorded as follows, starting from the termination of anaesthesia:

(a) "Open eyes" was defined as the time until the patient first opened her eyes spontaneously.

(b) "Orientation" was defined as the time when the patient was first able to recall her date of birth.

(c) "Sit up" time was when the patient was first able to sit up unaided.

All patients were observed closely for at least one hour in the postanaesthesia recovery room, and any complications or side effects were recorded. Thereafter all patients remained in the ward for at least three hours postoperatively. Before discharge from hospital information about side effects or complications was solicited and all patients were asked to complete and return a questionnaire on the day following the operation. This was designed to assess the occurrence of dreams during anaesthesia, the incidence of nausea and vomiting after discharge from the hospital, and the patient's overall assessment of the anaesthetic. In addition, an indication of subjective recovery time was obtained from their answer to the question, "How long after the operation did you feel completely recovered from the anaesthetic?"

\section{Laboratory data}

Blood samples were obtained preoperatively, and at one and four hours postoperatively for analysis of electrolytes, blood sugar, blood urea nitrogen (BUN), creatinine, bilirubin, alkaline phosphatase, serum glutamic oxaloacetic transaminase (SGOT), serum gamma glutamyl transpeptidase (SGGT), lactic dehydrogenase (LDH), and creatinine phosphokinase (CPK). Urinalysis and complete blood count (CBC) were done before and after operation.

\section{Statistical analysis}

Physiological variables and laboratory results were analyzed using a two-way analysis of variance and Dunnett's t-test. Differences between the two groups were not analyzed statistically due to their non-random generation.

\section{RESULTS}

Table I shows that the mean age and weight of patients are similar for both groups. The mean induction dose for Group 1 was $0.63 \mathrm{mg} \cdot \mathrm{kg}^{-1}$ compared with $0.93 \mathrm{mg} \cdot \mathrm{kg}^{-1}$ for Group II. Thirteen patients in Group I required incremental doses compared with five in Group II. In addition, two patients in Group II received fentanyl. The mean total dose of Minaxolone was $0.82 \mathrm{mg} \cdot \mathrm{kg}^{-1}$ in Group I and $1.02 \mathrm{mg} \cdot \mathrm{kg}^{-1}$ in Group II.

Physiological variables during Minaxolone anaesthesia are shown in Figure 1.

$P u l s e$ rate increased approximately 18 per cent during induction of anaesthesia and remained ele vated throughout the anaesthetic.

Systolic blood pressure decreased slightly during the first three minutes of anaesthesia to 10 per cent below the preoperative level, after which it rose to reach a plateau at eight minutes, slightly above pre-induction values. In one patient, there was a transient drop to approximately 30 per cent below the pre-operative value.

Diastolic blood pressure followed a similar pattern, falling 14 per cent below pre-induction levels at three minutes, and subsequently rising to reach a plateau at eight minutes, seven per cent above the pre-induction value.

Respiratory rate increased progressively during the first five minutes of anaesthesia to 

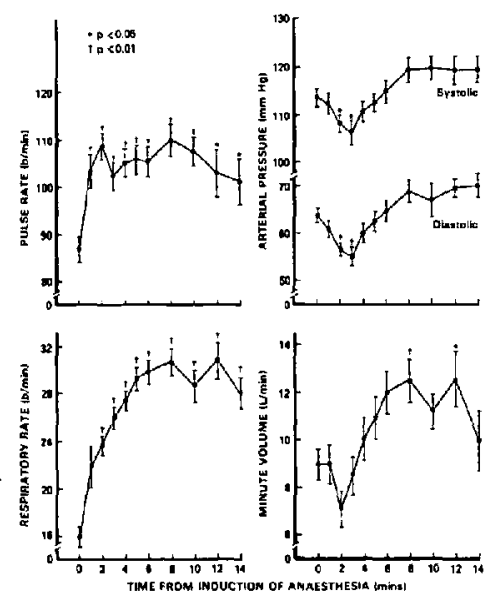

FIGURE I The change in five parameters during the first 14 minutes after induction of anaesthesia is shown as mean values \pm I S.E. Significant differenccs are indicated.

stabilize approximately 80 per cent above preinduction levels.

Minute volume decreased slightly following induction of anaesthesia, reaching a minimum value at two minutes. Over the next three minutes, it increased to approximately 33 per cent above pre-induction levels. A brief period of apnoea occurred in one paticnt immediately after induction.

Recovery times are displayed in Table II, and are slightly higher in Group II compared to Group I. The mean "orientation" time for all patients was 26.2 minutes, and mean "sit up" time was 31.1 minutes. Subjective recovery time averaged 1.95 hours.

\section{Side effects and complications}

Side effects occurring during induction and maintenance of anaesthesia are shown in Table III. Major cvents were those which were of clinical concern and did not respond to an increment of Minaxolone or fentanyl. Events which were of clinical concern but which readily responded to an inctement of Minaxolone or fentanyl were deemed moderate. Minor events were those which were of no clinical consequence.

No patient developed major clinical events. Four patients developed moderate coughing readily responding to an increment of $\mathrm{Mi}$ naxolone or fentanyl. Minor events included hiccough, transient coughing, mild laryngospasm, minor excitatory movements and skin rash. No patient complained of pain on injection of Minaxolone.
Clinical events occurring during recovery from anaesthesia are shown in Table IV and were graded thus: major if they required intervention of the anaesthetist; moderate if they required the specific attention of the recovery room nurse; minor if deemed to be of no clinical significance. No major events occurred during the recovery phase. Three patients developed marked hypertonus or excitatory movements, two were quite restless but responded to administration of an analgesic, and one was very tearful. All events in the recovery room occurred in the early recovery period with the exception of one patient who was nauseated. In general. the quality of recovery was impressive. Following discharge from the recovery room, all patients experienced a rapid, uneventful recovery. One patient experienced transient nausea in the ward on sitting up.

\section{Laboratory data}

Laboratory data are shown in Table $\mathrm{V}$.

The following tests showed no significant change between pre- and postoperative values: serum chloride, creatinine, bilirubin, CPK, SGGT, LDH, and alkaline phosphatase. Table V shows the tests in which statistically significant differences were shown. These changes were small and the values remained within normal limits.

The haematological tests were unchanged apart from haemoglobin. haemotocrit and red blood cell count, which showed a slight drop consistent with the small amount of blood loss associated with these procedures.

One patient had an elevated LDH of 700 units at four hours, compared to a pre-operative level of 144. There were no other significant enzyme changes in this patient.

Eleven patients showed urinary ketones in the post-operative urine specimens. There were no other clinically significant changes in the urinalysis which could not be explained by contamination from post-operative vaginal bleeding.

\section{Postoperative questionnaire}

Twenty-five patients ( 83 per cent) returned completed questionnaires. Seventeen patients commented favourably on the anaesthetic and seven of these commented specifically that it was superior to previous anaesthetics. There were no negative comments regarding the Minaxolone anaesthetic. No patient had a major problem after discharge from hospital; one patient vomited, one patient was nauseated and a third reported a headache. 
TABLE II

Duration of Anaesthesia and Recovery Times Are Shown In Minutes \pm 1 S.D. "SURJective" ReCOVERY TIME IS IN HOURS

\begin{tabular}{lccccr}
\hline \hline & $\begin{array}{c}\text { Duration of } \\
\text { anaesthesia }\end{array}$ & Open eyes & Orientation & Sit up & Subjective \\
\hline Group I & 12.09 & 16.34 & 24.63 & 27.42 & 2.32 \\
& \pm 4.22 & \pm 7.376 & \pm 8.614 & \pm 9.246 & \pm 1.18 \\
Group II & 11.64 & 18.67 & 28.23 & 34.28 & 1.65 \\
& \pm 3.41 & \pm 9.210 & \pm 10.786 & \pm 10.572 & \pm 1.33 \\
All patients & 11.86 & 17.75 & 26.23 & 31.11 & 1.95 \\
& \pm 3.778 & \pm 7.914 & \pm 9.570 & \pm 10.386 & \pm 1.26 \\
\hline
\end{tabular}

TABLE III

Events Occurring During Induction and Maintenance of Anaesthesia, Excluding Movement In Response To Surgical Stimulus

\begin{tabular}{lccccc}
\hline & \multicolumn{2}{c}{ Induction } & & \multicolumn{2}{c}{ Maintenance } \\
\cline { 2 - 3 } \cline { 5 - 6 } & Minor & Moderate & & Minor & Moderate \\
\hline Apnoea & 1 & 0 & & 0 & 0 \\
Hiccough & 1 & 0 & & 5 & 0 \\
Cough & 0 & 1 & & 3 & 3 \\
Salivation & 0 & 0 & & 2 & 0 \\
Laryngospasm & 0 & 0 & & 2 & 0 \\
Excitatory movement & 1 & 0 & & 6 & 0 \\
Skin rash/flush & 0 & 0 & & 3 & 0 \\
\hline
\end{tabular}

TABLE IV

Events Occurring During Recovery From Anaestuesia

\begin{tabular}{lccccc}
\hline & \multicolumn{2}{c}{$0-1$ hour } & & \multicolumn{2}{c}{$>1$ hr to discharge } \\
\cline { 2 - 3 } & Minor & Moderate & & Minor & Moderate \\
\hline Hiccough & 5 & 0 & & 0 & 0 \\
Cough & 2 & 1 & & 0 & 0 \\
Salivation & 2 & 0 & & 0 & 0 \\
Restlessness & 2 & 2 & & 0 & 0 \\
Crying & 2 & 1 & & 0 & 0 \\
Hypertonus/ & 7 & 3 & & 0 & 0 \\
$\quad$ excitatory movement & 1 & 0 & & 1 & 0 \\
Nausea & 0 & 0 & & 0 & 0 \\
Vomiting & 3 & 0 & & 0 & 0 \\
Skin rash/flush & & & & &
\end{tabular}

\section{Discussion}

This report describes the results of a Phase 11 evaluation of Minaxolone. Due to the early stage of clinical investigation, the drug was used as a sole anaesthetic agent, apart from nitrous oxide. The results of such a study cannot, therefore, be expected to compare favourably, in terms of the incidence of side effects and quality of anaesthesia, with other established intravenous agents when used as a part of a balanced technique. Such a technique would at least include the use of an analgesic, either preoperatively or during operation.

The rate of infusion employed in this study was approximately $6.5 \mathrm{ml}(32.5 \mathrm{mg})$ per minute. At this infusion rate, the use of loss of consciousness (as judged by lack of response to verbal command) as an end-point did not result in adequate anaesthesia since 13 patients ( 87 per cent) required further increments of Minaxolone, usually shortly after induction. The subsequent use of 
TABLE V

LABORATORY RESULTS (MEAN \pm 1 S.D.)

\begin{tabular}{llccc}
\hline \hline & & & \multicolumn{2}{c}{ Postoperative } \\
\cline { 4 - 5 } \multicolumn{1}{c}{ Test } & Units & Preoperative & $1 \mathrm{~h}$ & $4 \mathrm{hrs}$ \\
\hline Sodium & $\mathrm{mmol} / \mathrm{l}$ & $136.8 \pm 2.8$ & $135.3 \pm 3.1 \dagger$ & $135.3 \pm 3.8$ \\
Potassium & mmol/l & $4.09 \pm 0.43$ & $3.53 \pm 0.74 \dagger$ & $3.70 \pm 0.45 \dagger$ \\
Sugar & mg per cent & $89.4 \pm 19.3$ & $115.8 \pm 22.6 \dagger$ & $115.0 \pm 46.6^{*}$ \\
Calcium & mg per cent & $9.18 \pm 0.41$ & $8.66 \pm 0.59 \dagger$ & $8.63 \pm 0.47 \dagger$ \\
BUN & mg per cent & $9.33 \pm 2.89$ & $8.63 \pm 2.62 \dagger$ & $8.35 \pm 2.27 \dagger$ \\
Albumin & gm per cent & $3.71 \pm 0.38$ & $3.45 \pm 0.32^{*}$ & $3.26 \pm 0.42 \dagger$ \\
SGOT & units & $21.7 \pm 7.0$ & $18.35 \pm 4.5 \dagger$ & $18.19 \pm 3.7 \dagger$ \\
Haemoglobin & g/dl & $12.65 \pm 1.00$ & $12.14 \pm 1.18^{*}$ & - \\
Hct & per cent & $37.4 \pm 2.8$ & $35.8 \pm 3.5^{*}$ & - \\
RBC & $10^{12} / 1$ & $4.14 \pm 0.31$ & $4.01 \pm 0.42^{*}$ & - \\
\hline
\end{tabular}

$* p<0.05$.

$\dagger p<0.01$

loss of the eyelash reflex as the end-point for induction was preferable since only five patients (33 per cent) required a further increment of Minaxolone; but the mean induction dose was increased in that case by approximately 50 per cent to $0.93 \mathrm{mg} \cdot \mathrm{kg}^{-1}$. One would anticipate that the concomitant use of analgesics, administered either as a premedicant or intravenously, would reduce the induction dose of Minaxolone. Similarly, it is anticipated that a lower dose of Minaxolone would be adequate for induction of anaesthesia if followed by inhalational anaesthesia.

Minaxolone anaesthesia produced only mini$\mathrm{mal}$ depression of blood pressure and ventilation immediately after induction. The lack of clinically significant respiratory depression is a highly desirable property for an induction agent. The increase in pulse rate of approximately 18 per cent was due in part to lack of analgesia and light anaesthesia, but may also be a direct effect of Minaxolone. The marked increase in respiratory rate is also partly due to light anaesthesia and would likely be reduced by the use of analgesics.

Recovery times indicate that Minaxolone has a slightly longer duration of action than other intravenous agents such as thiopentone, methohexitone and Alfathesin. However, the quality of recovery was impressive and there was no evidence of the "hang over" commonly seen following thiopentone anaesthesia.

No major side effects occurred either during or after operation. The high incidence of mild or moderate side effects during operation, and other minor respiratory disturbances was undoubtedly due in part to light anaesthesia, lack of analgesia, and absence of vagolytic agents. In a previous study ${ }^{4}$ of Alfathesin using a similar protocol, a similar high incidence of side effects was reported. The incidence of excitatory movements during operation was 23 per cent, which is rather high considering the relatively slow rate of administration. A similar incidence of excitatory movements and hypertonus was seen in the recovery period, although none of these caused clinical concern. When compared with the previous study. ${ }^{4}$ the incidence of excitatory effects was more frequent than with Alfathesin.

The longer term recovery from Minaxolone anaesthesia was uneventful and impressive, both in quality of recovery and in the very low incidence of problems experienced. Patient acceptance of the drug was very high.

Post-operative laboratory tests showed some changes. Haemoglobin, haematocrit, sodium, potassium, calcium, blood urea, albumin, and SGOT showed reductions which were of statistical significance. Blood glucose showed a postoperative increase which was also highly significant statistically. From a clinical perspective, none of these changes were important and are likely due to administration of intravenous fluids and blood loss. One patient showed a five-fold elevation of serum LDH four hours postoperatively. The implication of this finding is unclear since no abnormalities were found in other enzymes studied. Although there is no reason to believe that Minaxolone was responsible for any of the laboratory changes, this possibility cannot be completely excluded in the absence of similar laboratory data following the use of other intravenous anaesthetics in a comparable study 
population. A further study using a comparative design is therefore required to elucidate this question further.

The results of this study are comparable to the two previously published reports ${ }^{5.6}$ of the use of Minaxulone in patients. The induction dose was higher in the present study, possibly due to the different injection rate and ages of the patients studied. The incidence of side effects, apart from excitatory movements, appear to be similar in all the studies. The incidence of excitatory movements appears to be lower in this study, perhaps due to the slower rate of induction. The changes in cardiovascular and respiratory variables are comparable to those reported by Aveling. ${ }^{5}$ The higher incidence of postoperative hypertonus and excitatory movements noted in this study may be due to the relatively higher doses of Minaxolone used, which would be expected to result in higher blood levels during initial recovery.

In summary, Minaxolone appears to be a safe and effective intravenous anaesthetic with impressive recovery characteristics. Its only drawback would seem to be its high incidence of excitatory movements and hypertonus. It appears to be a promising intravenous anaesthetic agent worthy of further clinical investigation.

\section{ACKNOWLEDGEMENTS}

The authors wish to acknowledge the cooperation of their colleagues in the Departments of Anaesthesia and Gynaecology, and the staff of the operating room at McMaster University Medical Centre. Thanks are due to Ms. S. Seaman for typing the manuscript, and Glaxo Canada (Ltd.) for supplies of Minaxolone and for financial support.

\section{REFERENCES}

1. SELYE, H. Studies concerning anaesthetic action of steroid hormones. J. Pharmacol. Exp. Ther. 73: 127 (1941).

2. DundeE, J.W. Hypersensitivity to intravenous anaesthetic agents. $\mathrm{Br}$. J. Anaesth. 48: 57 (1976).

3. Davis, B., Dodds, M.G., Dolamore, P.G., Gardner, C.J., Sawyer, P.R. et al. Minaxolone: a new water-soluble steroid anaesthetic. Br. J. Anaesth. 51: 564P (1979).

4. Dunn. G.L., Houlton. P.J., Morison, D.H. \& RAJAGOPALAN, R. The influence of fentanyl on an alfathesin infusion technique. Canad. Anaes. Soc. J. 24: 33l (1978).

5. AVEling, W., Fitch, W., Waters, A., Simpson, P. Prys-Roberts, C., et al. Early clinical evaluation of Minaxolone: a new intravenous steroid anaesthetic agent. The Lancet 71 (1979).

6. MCNeill, H.G. Clarke, R.S.J. \& DundeE, J.W. Minaxolone: a new water-soluble steroid anaesthetic. The Lancet 73 (1979).

\section{RÉSUMÉ}

Un nouvel anesthésique stêroide soluble dans l'eau, le minaloxone a étć étudié en association avec le protoxyde d'azote chez 30 patients en bonne santé. L'objectif de l'étude consistait à évaluer la dose d'induction. l'efficacité, la récupération et l'incidence des effets secondaires. L'agent anesthésique s'est montré efficace toul en ne causant que peu de dépression cardiovasculaire et respiratoire. Les effets secondaires survenus pendant l'opération semblent avoir été causés par une anesthésie trop légère ou un manque d'analgésie. De l'excitation et l'hypertonie sont survenus chez 7 patientes pendant l'intervention et sur 10 patientes pendant la récupération précoce. Les auteurs ont été favorablement impressionnés tant par la qualité de la récupération tardive que par l'absence d'effets secondaires pendant cette période et toutes les patientes ont pu quitter l'hôpital dans les quatre heures qui ont suivi l'opération. Le minaxolone semble done çtre un nouvel agent prometteur et devrait être étudié plus à fond. 